\title{
Overview of recent work on precipitation in Al-Cu-Mg alloys
}

\author{
S.C. Wang ${ }^{a}$, M.J. Starink ${ }^{b}$, N. Gao ${ }^{c}$ \\ Materials Research Group, School of Engineering Sciences, University of Southampton, \\ Southampton, SO17 1BJ, United Kingdom \\ awangs@soton.ac.uk, ${ }^{\mathrm{b}} \mathrm{m} . j . s t a r i n k @ s o t o n . a c . u k,{ }^{c}$ n.gao@soton.ac.uk,
}

Keywords: Al-Cu-Mg alloys, clusters, precipitates, hardening.

\begin{abstract}
Recent work on $\mathrm{Al}-\mathrm{Cu}-\mathrm{Mg}$ based alloys with $\mathrm{Cu}: \mathrm{Mg}$ atomic ratio close to unity is reviewed to clarify the mechanisms for age hardening. During the first stage of hardening a substantial exothermic heat evolution occurs whilst the microstructural change involves the formation of initially $\mathrm{Cu}$-rich / Mg-rich clusters and later $\mathrm{Cu}-\mathrm{Mg}$ co-clusters. The data show that the first stage of the age hardening is due to the formation of $\mathrm{Cu}-\mathrm{Mg}$ co-clusters. The combined experimental methods show the second stage hardening is dominated by formation of $\mathrm{S}$ phase, which forms a dense precipitation at the peak hardness stage, whilst no significant amounts of other phases or zones are detected. S phase strengthens the alloy predominantly through the Orowan looping mechanism. These findings are incorporated into a multi-phase, multi-mechanism model for yield strength of $\mathrm{Al}-\mathrm{Cu}-\mathrm{Mg}$ based alloys.
\end{abstract}

\section{Introduction}

$\mathrm{Al}-\mathrm{Cu}-\mathrm{Mg}$ based alloys are widely used in structural applications, in particular alloys with $\mathrm{Cu}: \mathrm{Mg}$ atomic ratio close to 1 are used extensively in aerospace applications, in which these alloys display excellent combinations of strength and fatigue resistance as well as good stability of properties on aerodynamic heating to $100-130^{\circ} \mathrm{C}$. For instance, the 2024 alloy with composition of about Al-1.8Cu-1.7Mg-0.3Mn (at-\%), and derivatives 2124 and 2524 , are primary structural material used in aircraft. $2 \times 24$ alloys continue to be specified for many aerospace structural applications, such as in fuselage structures, wing tension members, shear webs and ribs. Alloy 2024 was first introduced by Alcoa in 1931 as an alclad sheet in the T3 temper (natural aged, i.e. aged at room temperature), and now is available in bare and alclad sheet and plate product forms in natural ageing T3/T4 (room temperature) or artificial ageing (T6/T8).

It has been noticed since 1950s that age hardening of $\mathrm{Al}-\mathrm{Cu}-\mathrm{Mg}$ alloys occurs in two distinct stages, which are separated by a plateau. The first stage is a rapid hardness increase which occurs within 1 min of ageing at temperatures of about $100-200^{\circ} \mathrm{C}$ for solution treated and water quenched (STWQ) samples. The second stage is the rise to peak hardness. An example is shown in Fig. 1 with ageing temperature $\left(\mathrm{T}_{1}\right)$ at $150^{\circ} \mathrm{C}$ for an $\mathrm{Al}-1.08 \mathrm{Cu}-1.14 \mathrm{Mg}$ (at-\%) alloy [1]. The first stage of hardening may account for $\sim 60 \%$ of maximum hardening. For ageing at lower temperatures the precipitation reaction is too sluggish to proceed beyond the first stage. An example is shown in Fig. 1 with ageing temperature $\left(\mathrm{T}_{0}\right)$ at $25^{\circ} \mathrm{C}$ (room temperature) for an $\mathrm{Al}-1.21 \mathrm{Cu}-1.20 \mathrm{Mg}-0.21 \mathrm{Mn}$ (at-\%) alloy [2]. As the ageing temperature is increased above a critical temperature, age-hardening takes place in a single stage, leading directly to a hardness peak. The example is shown in Fig. 1 with ageing temperature $\left(\mathrm{T}_{2}\right)$ at $240^{\circ} \mathrm{C}$ for an $\mathrm{Al}-1.13 \mathrm{Cu}-1.54 \mathrm{Mg}$ (at-\%) alloy [3].

In studies on a range of different $\mathrm{Al}-\mathrm{Cu}-\mathrm{Mg}$ based alloys, several explanations for the first stage of hardening were suggested. The main four mechanisms are strengthening due to I) GPB (Guinier-Preston-Bagaryatskii) zone formation; II) Cu-Mg co-cluster formation [4]; III) locking of existing dislocations due to a solute-dislocation interaction (suggested on the basis of three-dimensional atom probe (3DAP) data [5]); and IV) formation of S" phase on dislocations indicated by selected area diffraction (SAD) patterns [6]. 
Mechanism I was favoured from 1950s to mid 1990s (for example, X-ray diffraction (XRD) data from single crystals was interpreted in terms of GPB zones [7]) and also more recent work has invoked this explanation (see e.g. high resolution electron microscopy (HREM) work in [8,9]). Mechanism II has been proposed since the mid 1990s by groups working with atom probe field ion microscopy (APFIM).

The previous work in the literature attributed the second stage of hardening to the formation of the GPB zones $+\mathrm{S}$ for ageing at $110-190^{\circ} \mathrm{C}$ and $\mathrm{GPB} 2+\mathrm{S}$ for ageing at $240^{\circ} \mathrm{C}$ (based on XRD patterns obtained from single crystal ${ }^{1}$ [7错误! 未定 义书签。 ]). In the 1980's, Cuisiat et al. [10] suggested that a distinct precipitate termed $\mathrm{S}$ " was responsible for the peak hardness. In the 1990s, using HREM, Ringer et al. $[4,11]$ proposed that the second-stage hardening (peak) is due to the formation of GPB zones. Obviously there are some controversies to the mechanism of the hardening, both in the initial and peak stages.

The works cited above refer mostly to high purity $\mathrm{Al}-\mathrm{Cu}-\mathrm{Mg}$ alloys. It is conceivable that the reaction is to some extent influenced by the presence of small amounts of impurities, such as Fe or $\mathrm{Si}$ [12] beside $\mathrm{Cu} / \mathrm{Mg}$ ratio [2]. Nevertheless, there is an agreement based on experiments that in the

$+\mathrm{S}$ field of $\mathrm{Al}-\mathrm{Cu}-\mathrm{Mg}$ alloys, $\mathrm{Cu}: \mathrm{Mg}$ ratios and impurities do not substantially alter the ageing sequences, although changes in formation rate in precipitates may be induced by these factors.

In this paper, we will review recent work on $\mathrm{Al}-\mathrm{Cu}-\mathrm{Mg}$ based alloys with $\mathrm{Cu}: \mathrm{Mg}$ atomic ratio close to unity to clarify the mechanisms for age hardening in both stages. The focus will be mostly on an Al-1.21 Cu-1.20Mg-0.21Mn (at.\%) alloy, for which we have extensive on differential scanning calorimetry (DSC), 3DAP, transmission electron microscopy (TEM) and mechanical testing data. Following on from the analysis of the microstructure and microstructural development, a quantitative model to predict the rapid hardening and peak strengthening is considered.

\section{Initial hardening}

No precipitates or structures reminiscent of GPB zones have been observed by 3DAP during room temperature hardening up to $24 \mathrm{~h}$, but clustering of solute atoms can be identified. Fig. 2 highlights the distribution of the $\mathrm{Cu}-\mathrm{Mg}$ co-clusters in the $\mathrm{Al}-1.21 \mathrm{Cu}-1.20 \mathrm{Mg}-0.21 \mathrm{Mn}$ alloy aged at $25^{\circ} \mathrm{C}$ for $2 \mathrm{~h}$ after water quenching [2]. The density in clusters has been found to increase from $1.3 \pm 1 \times 10^{23}$ at 30 min to $4.6 \pm 1.2 \times 10^{23}$ clusters at $3.5 \mathrm{~h}$ per $\mathrm{m}^{3}$ (open rectangles in Fig. 3 ). For ageing beyond $10 \mathrm{~h}$ the density stays stable or decreases slightly. The hardness evolution during ageing at $25^{\circ} \mathrm{C}$ of solution treated samples shows a rapid hardening (Fig. 3) between 1 and $20 \mathrm{~h}$. 3DAP analysis [13] shows that up to $2 \mathrm{~h}$ ageing at $25^{\circ} \mathrm{C}$ after STWQ the clusters are $\mathrm{Mg}$-rich and $\mathrm{Cu}$-rich. As the time of natural ageing increases, $\mathrm{Cu}-\mathrm{Mg}$ co-clusters appear. The $\mathrm{Cu}: \mathrm{Mg}$ ratio of these co-clusters is about 1 . This

\footnotetext{
${ }^{1}$ Recent work has shown that S' precipitates and S phase are essentially identical in terms of crystal structure and we will here identify them as a single phase, termed $S$ phase.
} 
indicates that the $\mathrm{Cu}-\mathrm{Mg}$ co-clusters are the cause of the initial rapid hardening, whereas there is no evidence that the initial $\mathrm{Cu}$-rich and $\mathrm{Mg}$-rich clusters contribute the strengthening.

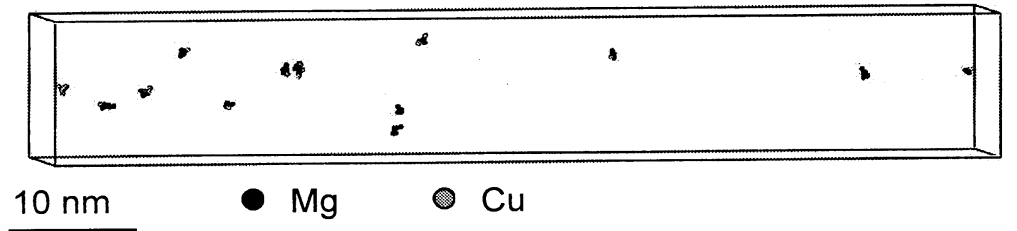

Fig. 2 3DAP results representing the distribution $u$ un $\mathrm{Mg}$ and $\mathrm{Cu}$ atoms that are part of co-clusters that are larger than a minimum of 7 detected atoms in the $\mathrm{Al}-1.21 \mathrm{Cu}-1.20 \mathrm{Mg}-0.21 \mathrm{Mn}$ alloy aged at $25^{\circ} \mathrm{C}$ for $2 \mathrm{~h}$. The size of the atoms has been increased to make the clusters more visible and it is not proportional to the size of the atoms (adapted from [2]).

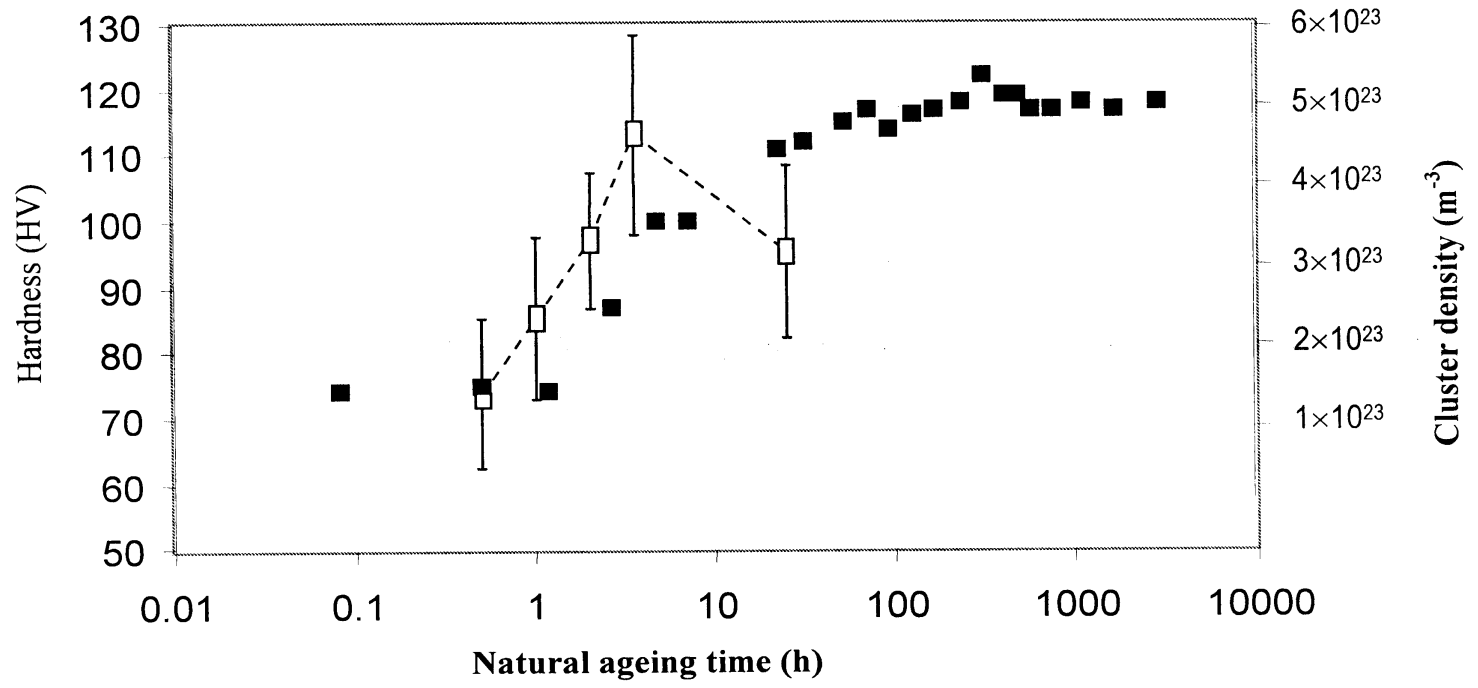

Fig. 3 Natural age hardening and estimated cluster density $\left(\right.$ per $\left.\mathrm{m}^{3}\right)$ during ageing at $25^{\circ} \mathrm{C}$ of the solution treated and quenched Al-1.21 Cu-1.20Mg-0.21Mn (at-\%) alloy. Solid squares represent hardness (reported in [2]), and the open rectangles represent density of clusters with uncertainty (reported in [13]).

DSC experiments performed after ageing for $5 \mathrm{~min}$ to 7 days at $25^{\circ} \mathrm{C}$ after STWQ are presented in Fig. 4 [14]. Four effects (two exothermic and two endothermic), numbered I to IV, are evident. The DSC curves show that effect I decreases with the natural ageing time and this effect has disappeared after 10h. 3DAP [13] has shown that initially $\mathrm{Cu}$-rich and $\mathrm{Mg}$-rich clusters form up to $2 \mathrm{~h}$ ageing, and later $\mathrm{Cu}-\mathrm{Mg}$ co-clusters are dominant. Therefore, the peak I is attributed to cluster and co-cluster formation, with the formation of $\mathrm{Cu}-\mathrm{Mg}$ co-clusters, which have a relatively high enthalpy of formation [15], probably being dominant. It is known that the clusters are still present after ageing at $150^{\circ} \mathrm{C}$ for several hours and that the clusters will disappear at about $190^{\circ} \mathrm{C}[16,17]$. Hence the endothermic effect II, between $150^{\circ} \mathrm{C}$ and $250^{\circ} \mathrm{C}$, is thought to be due to the dissolution of the clusters. Effects III and IV, identified as due to $\mathrm{S}$ phase formation and $\mathrm{S}$ phase dissolution respectively, will be discussed below.

\section{Peak hardening}

$\mathrm{DSC}$ data for the $\mathrm{Al}-1.21 \mathrm{Cu}-1.2 \mathrm{Mg}-0.21 \mathrm{Mn}$ alloy in $\mathrm{T} 351$ condition and heat treated at $190^{\circ} \mathrm{C}$ for $6 \mathrm{~h}$ $/ 12 \mathrm{~h}$ is shown in Fig. 5 [18]. Three main peaks may be identified in the T351 thermogram. The endothermic peak II is attributed to clusters dissolution. The exothermic peak III, between $250^{\circ} \mathrm{C}$ and $300^{\circ} \mathrm{C}$, may be attributed to the formation of precipitates, a broad endothermic effect IV after $350^{\circ} \mathrm{C}$ is 
expected to be due to dissolution of the previously formed precipitates. For the sample aged for $6 \mathrm{~h}$ at $190^{\circ} \mathrm{C}$, effect II has completely disappeared and effect III has nearly disappeared. It means that the clusters have been dissolved and most of precipitates have formed during isothermal ageing for $6 \mathrm{~h}$ prior to the DSC run. After ageing for $12 \mathrm{~h}$, only the effect IV exists which indicates that full formation of the equilibrium precipitates occurred during artificial ageing before the DSC run. The hardness curve for ageing at $190^{\circ} \mathrm{C}$ (Fig. 6) shows that ageing at $190^{\circ} \mathrm{C}$ for 6 hours is just short of peak

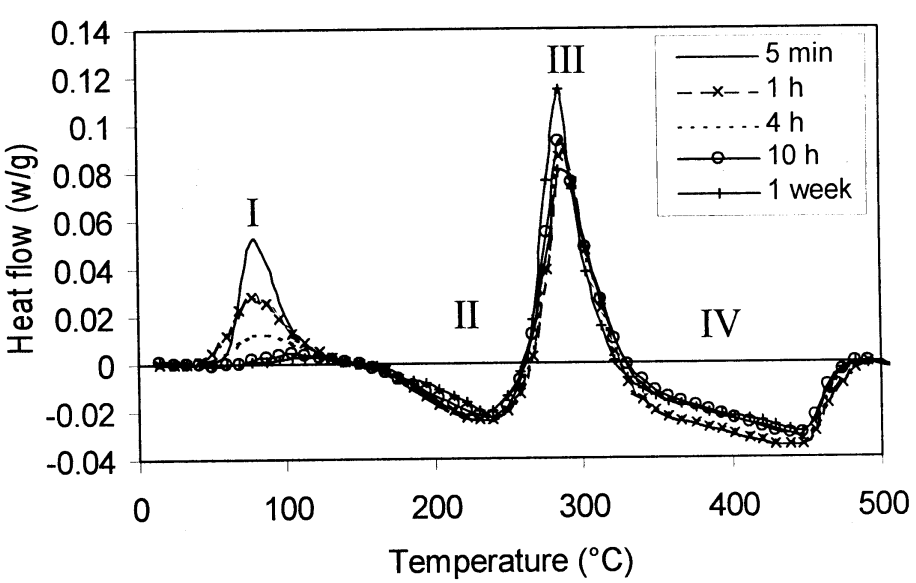

Fig. 4 DSC thermograms of the solution treated and quenched Al-1.21Cu-1.2Mg-0.21Mn (at-\%) alloy after ageing for several intervals ageing at $25^{\circ} \mathrm{C}$ (adapted from [14]) ageing and $12 \mathrm{~h}$ is at peak hardness. Therefore, the precipitates formed in peak III will be main hardening precipitates contributing to the peak hardness. A sample treated for $6 \mathrm{~h}$ at $190^{\circ} \mathrm{C}$ has been chosen for TEM observation. Fig. 7 shows lath-shaped precipitates (Fig. 7a) observed from [112] $]_{\mathrm{Al}}$ direction (Fig. 7b). Simulated diffraction patterns (Fig. 7c), based on 12 variants of $S$ phase using the generally accepted Perlitz-Westgren (PW) model [19] and the $\left(\begin{array}{lll}0 & 0 & 1\end{array}\right)_{\mathrm{S}} /\left(\begin{array}{lll}0 & 2 & 1\end{array}\right)_{\mathrm{Al}}$ orientation relation [20], match all spots in the [112] $]_{\mathrm{Al}} \mathrm{SAD}$ pattern (Figs. 7b, 7c). This indicates that $\mathrm{S}$ phase is the dominant precipitate after 6 hour ageing at $190^{\circ} \mathrm{C}$ and that $\mathrm{S}$ phase formation is responsible for the second stage of hardening for quenched and stretched $\mathrm{Al}-\mathrm{Cu}-\mathrm{Mg}$ alloys. The peak strengthening was related to the formation of $\mathrm{S}$ in $\mathrm{Al}-\mathrm{Cu}-\mathrm{Mg}$ alloys regardless of being stretched or not stretched [ 错误 ! 未定义书签。,21], in contrast to GPB suggested in Ref. [11].

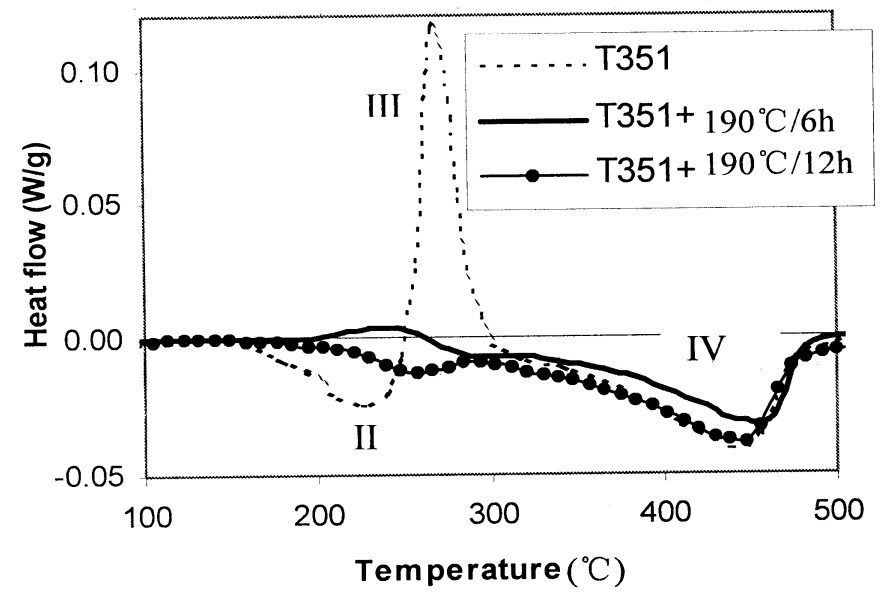

Fig. 5 DSC thermogram of an Al-1.21Cu-1.2Mg-0.21Mn (at-\%) alloy in stretched condition (T351), and after subsequent ageing for $6 \mathrm{~h}$ and $12 \mathrm{~h}$ at $190^{\circ} \mathrm{C}$ (from [错误! 未定义书签。]).

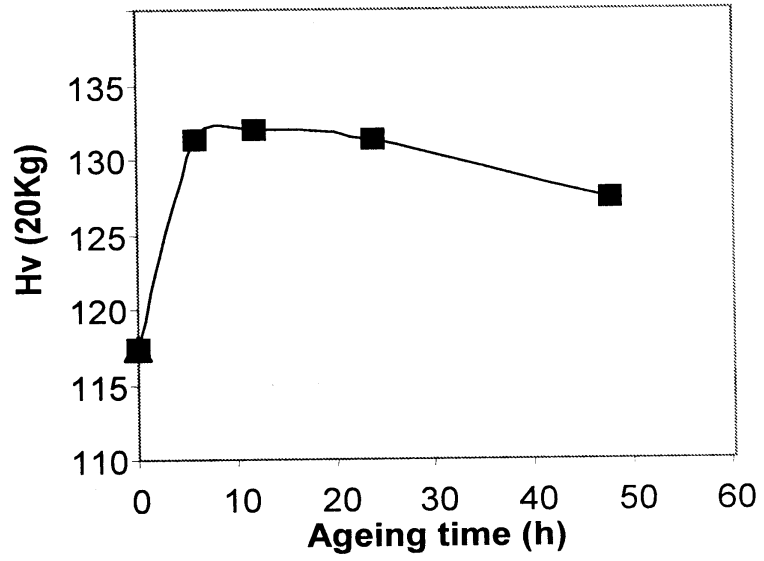

Fig. 6 Hardening-time curves of the Al-1.21Cu-1.2Mg-0.21Mn (at-\%) alloy in stretched condition (T351) during ageing at $190^{\circ} \mathrm{C}$ (from [2]). 


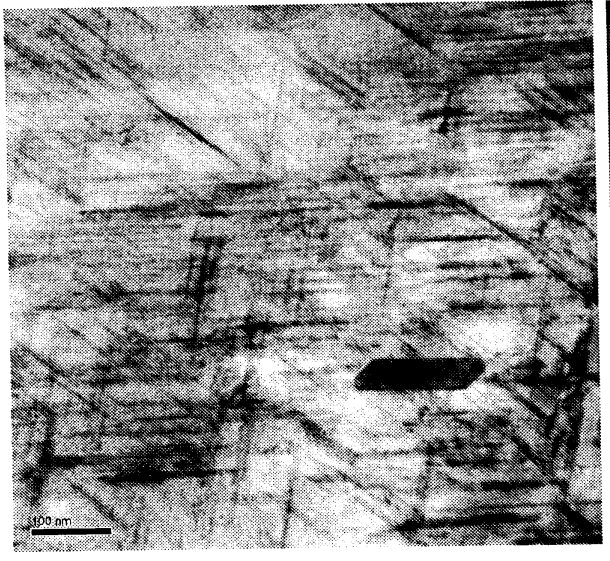

a

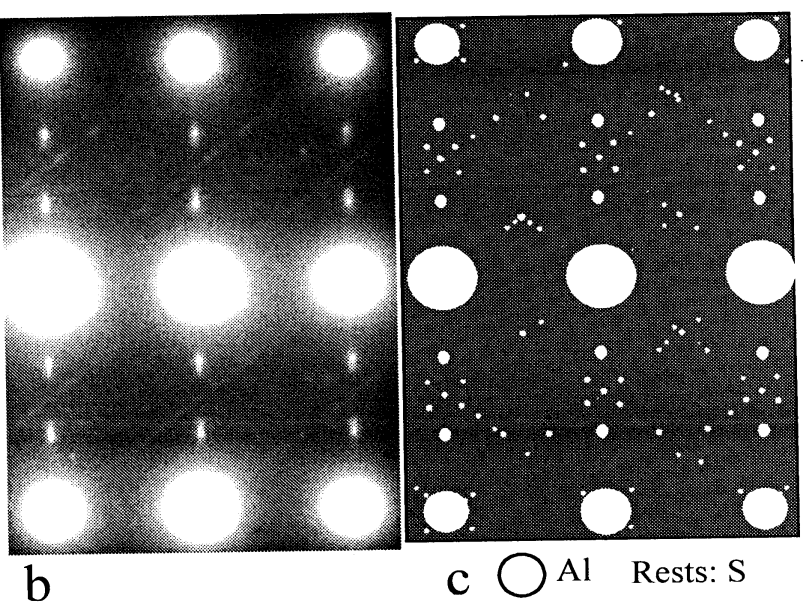

c $\bigcirc \mathrm{Al}$ Rests: $\mathrm{S}$

Fig. 7 TEM micrographs of precipitation in the Al-1.21 Cu-1.2Mg-0.21Mn (at-\%) alloy aged for $6 \mathrm{~h}$ at $190^{\circ} \mathrm{C}$. (a) Bright field, (b) [112] $]_{\mathrm{Al}}$ SAD pattern and (c) the simulated diffraction patterns of 12 variants of $\mathrm{S}$ phase in $[112]_{\mathrm{Al}}$, which correspond well with (b) (adapted from [20]).

\section{Evidence of GPB2/ S"}

The existence of a GPB2 or S" has proved to be controversial. A range of structures termed GPB2 or S" were suggested by various researchers to explain HREM, TEM or SAD observations, but none of the structures are considered to be unambiguously proven, and some researchers (i.e. [22,23]) have pointed out the weakness of some of the data used to support a distinct S"/GPB2 phase. Ambiguity might be related to limited contrast of any zones, which could be due to the size effects of $\mathrm{Cu}$ (radius $=0.128 \mathrm{~nm}$ ) and $\mathrm{Mg}$ atoms (radius $=0.160 \mathrm{~nm}$ ) counteracting each other.

In HREM work on an Al-0.87Cu-1.45Mg (at-\%) alloy that was solution treated and aged at $200^{\circ} \mathrm{C}$ for $4 \mathrm{~h}$, Charai et al. [9] found a coherent phase of $\sim 3 \times 10 \mathrm{~nm}$ as shown in Fig. 8a. The Fourier transformation (FT) in the area shows extra reflections besides aluminium reflections, whereas these extra diffractions cannot be observed form Al matrix as shown in Fig. 8b. These results, however, could not be elucidated by the previously suggested structures. Based on the low energy configuration of Wolverton for GPB zone, a new GPB2/S" structure in Fig. 8c was proposed [21]. The GPB2/S" has $\operatorname{Imm} 2$ structure and the lattice parameters are $a=0.405 \mathrm{~nm}, b=1.62 \mathrm{~nm}$ and $c=0.405 \mathrm{~nm}$. Its composition $\mathrm{Al}_{10} \mathrm{Cu}_{3} \mathrm{Mg}_{3}$ is between that of $\mathrm{S}$ phase $\left(\mathrm{Al}_{2} \mathrm{CuMg}\right)$ and $\mathrm{Cu}-\mathrm{Mg}$ clusters which have about 90\% Al [24]. The simulated image in $4 \mathrm{~nm}$ of thickness and diffractions in Figs. 8(d,e) match well the experimental image in Fig. 8(a,b). The size of the precipitate is derived to be $\sim 3 \times 4 \times 10 \mathrm{~nm}$.

Recently Kovarik et al. [23] suggested that the HREM image attributed to S" with a structure very different from S (Fig. 4 of Ref. [8]) can be simulated by overlapping of Al matrix and an S phase (PW model [19]) with a modified orientation relation with the matrix, with a Moiré and double diffraction effects contributing significantly to the image. However, only one particular geometry of S precipitate in $\mathrm{Al}$, with interfaces, was reported, and the orientation relationship used in the diffraction simulations was somewhat different from the observed orientation relationship of the coherent interface (found to be $(021) \mathrm{S} / /(014) \mathrm{Al})$. This can substantially alter the Moiré fringes. As both suggestions seem to be able to explain the observed HREM images, whilst definite proof of either is lacking, more experimental data will be needed come to firm conclusions. (We note here that to term the S phase with modified orientation relationship S" [23] can lead to confusion.) The appearance of the orthorhombic GPBII/S" seems to not influence the hardness significantly, at least in alloys which contain more than $1 \mathrm{wt} \% \mathrm{Cu}$. This could be due to the limited amount of GPBII/S" formed or to them having a similar hardening effect as the co-clusters they replace. 


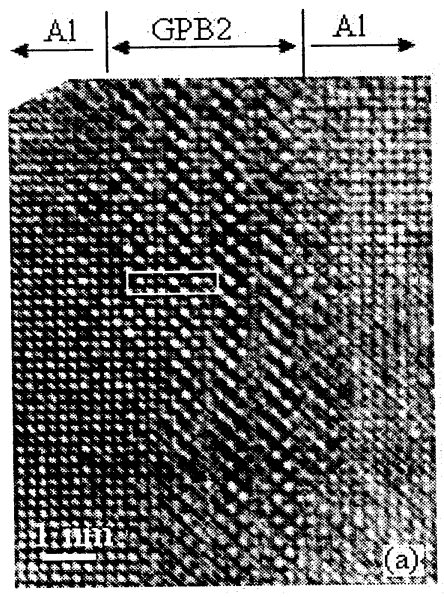

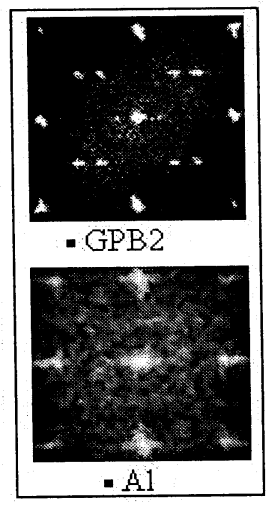

(b)

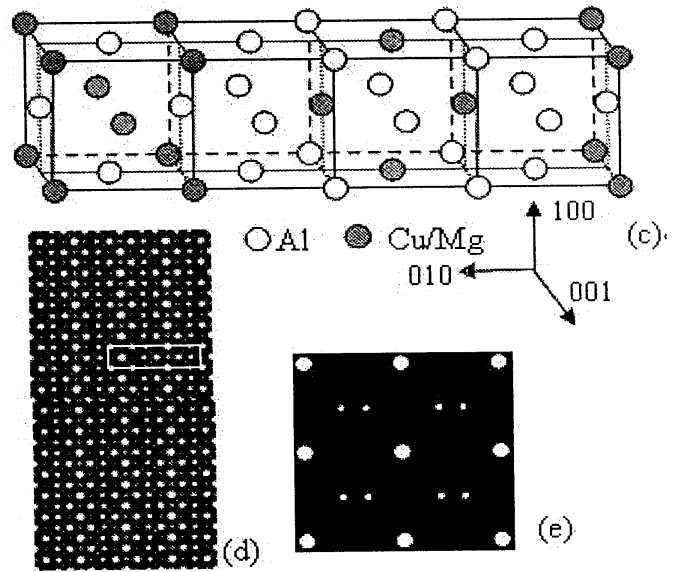

Fig. 8(a) and (b) HREM images and Fourier transformed diffraction pattern in $[100]_{\mathrm{Al}}$ after $200^{\circ} \mathrm{C}$ for $4 \mathrm{~h}$ in an Al-0.87Cu-1.45Mg (at-\%) (adapted from [9]) (c) A proposed GPB2/S" model; (d) HREM simulation along [001] based on the structure (c) at $200 \mathrm{kV}$ with Cs $=0.5 \mathrm{~mm}$ in $4 \mathrm{~nm}$ of thickness and defocus at $68 \mathrm{~nm}$; (e) Simulated [001] diffraction pattern based on the structure (c).(c, $d$ and e adapted from [21])

\section{The strength model}

In polycrystalline materials several hardening mechanisms operate, and the yield strength should generally be given by [25]:

$$
\sigma_{y}=\Delta \sigma_{G B}+M \cdot \tau_{t o t}
$$

where $\Delta \sigma_{\mathrm{GB}}$ is the grain boundary strengthening, $M$ is an orientation factor (often termed the Taylor factor), and $\tau_{\text {tot }}$ is the critical resolved shear stress (CRSS) of the grains which is determined by several strengthening mechanisms, most notably intrinsic hardening, precipitate hardening (including co-cluster hardening) and solution hardening.

The kinetics of formation of (co-)clusters is an atomic scale process that involves the interaction between $\mathrm{Al}, \mathrm{Cu}$ and $\mathrm{Mg}$ atoms and vacancies. Rather than attempting to fully capture the atomic scale effects involved, which is unlikely at present to lead to a model with predictive capabilities, we considered the kinetics of $\mathrm{Cu}-\mathrm{Mg}$ cluster based on a model of nucleation, growth and impingement of diffusion fields considers averaged properties [2]. A key point in the model is the assumption that $\mathrm{S}$ phase forms whilst the pre-precipitates dissolve.

The transformed fraction of precipitates during ageing can be described by the Starink-Zahra (SZ) model for nucleation and growth [26,27]:

$$
f(T, t)=1-\left(\frac{[k(T) t]^{n}}{\eta_{i}}+1\right)^{-\eta_{i}}
$$

where $f(T, t)$ is the transformed fraction, $n$ is the reaction exponent, $\eta_{i}$ is the impingement exponent and $k(T)$ is the rate constant which can be expressed by an Arrhenius relation. The size evolution during precipitation and subsequent coarsening is described by a treatment $[24,25]$ which interpolates between an extended volume approach (the SZ model) and coarsening theory (the LSW model modified for finite volume fraction) $[28,29]$.

The CRSS is given by:

$$
\tau_{\text {tot }}=\tau_{0}+\Delta \tau_{s s}+\left(\Delta \tau_{c l}^{q}+\Delta \tau_{s}^{q}\right)^{1 / q}
$$

where $\tau_{0}$ is intrinsic strengthening, $\Delta \tau_{s s}$ is solid solution strengthening, $\Delta \tau_{c l}$ is $\mathrm{Cu}-\mathrm{Mg}$ co-cluster strengthening, $\Delta \tau_{s}$ is $\mathrm{S}$ phase strengthening. The exponent $q$ is an adjustable parameter between 1 and 2. A non-linear superposition rule is applied in the latter equation as the obstacle strengths responsible for cluster strengthening and $\mathrm{S}$ strengthening are of a similar magnitude [25]. In contrast, solid solution strengthening is much smaller than strengthening due to co-clusters and precipitation, and hence a linear summation for the total hardening contributed to the yield stress is appropriate [30]. 
To obtain the individual CRSS, analytical expressions based on the literature are used: (a) The increment in CRSS due to solid solution strengthening, $\Delta \tau_{s s}$, is described by

$$
\Delta \tau_{s s}=\sum k_{j} \cdot c_{j}^{2 / 3}
$$

where $k_{\mathrm{j}}$ are the factors describing the strengthening due to the individual elements, and $c_{\mathrm{j}}$ are the concentrations of the alloying elements in solid solution.

(b) The hardening due to co-clusters is approximated by considering modulus hardening. The expression first proposed by Cartaud et al. [31] and later applied in several works on rapid hardening of Al based alloys [14], has been applied:

$$
\Delta \tau_{c l}=\frac{\Delta \mu}{4 \pi \sqrt{2}} f_{c l}^{1 / 2}
$$

where $\Delta \mu$ is the difference between the shear moduli of the matrix, $\mu_{m}$, and the clusters, $\mu_{c l}, f_{c l}$ is the volume fraction of the clusters. $\Delta \mu$ is obtained by fitting to yield strength data.

(c) $\mathrm{S}$ laths are considered to be non-shearable and bypassed by an Orowan looping mechanism, and strengthening is predicted to be [32]:

$$
\Delta \tau_{S}=\frac{0.81 G_{m} b}{2 \pi(1-v)^{1 / 2}} \ln (d / b)\left(0.615 d \sqrt{\frac{2 \pi}{3 f_{S}}}-d\right)^{-1}
$$

where $G_{m}$ is the shear modulus of matrix, $b$ is the Burgers vector for Al, $v$ is the Poisson's ratio for $\mathrm{Al}$, $f_{S}$ is the volume fraction of $\mathrm{S}$ phase and $d$ is the diameter of the cross-section of $\mathrm{S}$ phase.

A comparison between model predictions and experimental data for isothermal ageing in the range from 20 to $220^{\circ} \mathrm{C}$ shows very good agreement $[24,33]$ over the entire range from early (first stage hardening to coarsening. An example for room temperature hardening is presented in Fig. 9 (The yield strength in MPa is taken as 2.3 times the Vickers hardness value [17]). The good results obtained show that the present model, with precipitation hardening based on a two precipitate - two mechanism treatment, accounts fully for hardening in our $\mathrm{Al}-\mathrm{Cu}-\mathrm{Mg}$ alloys.

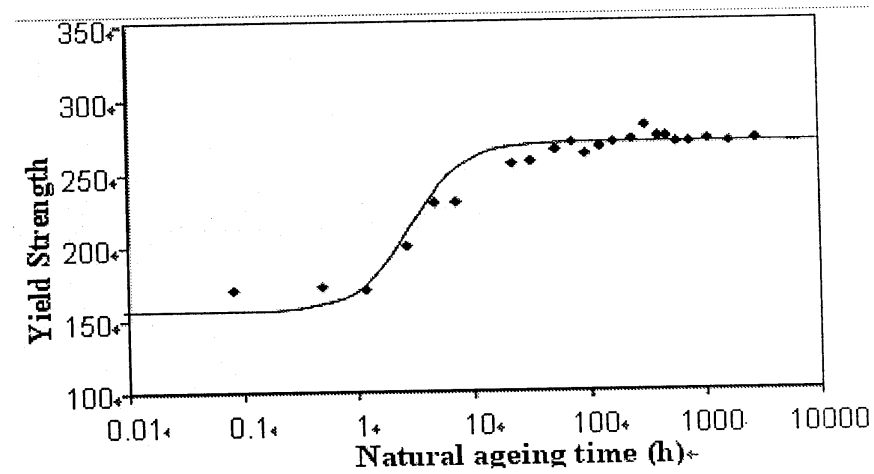

Fig. 9 Measured (diamond dots) strengths of the Al$1.21 \mathrm{Cu}-1.20 \mathrm{Mg}-0.21 \mathrm{Mn}(\mathrm{at}-\%)$ alloy and modelling results (solid line) (from [2])

\section{Concluding Remarks}

Hardness testing, DSC and 3DAP of commercial purity stretched Al-1.21Cu-1.20Mg-0.21Mn (at\%) has shown that $\mathrm{Cu}-\mathrm{Mg}$ co-clusters, which form after $2 \mathrm{~h}$ natural ageing, are responsible for the rapid hardening. Cu-rich and Mg-rich clusters, present before $\sim 2 \mathrm{~h}$ natural ageing after water quench, seem to be insignificant for the hardening. TEM analysis shows a dense precipitation of $\mathrm{S}$ phase occurs in the peak hardening condition, and the $\mathrm{S}$ phase is the main contributor to the peak hardness.

A model for age hardening due to the kinetic formation of two types of precipitates, co-clusters and $\mathrm{S}$ phase, is developed to predict the hardening. The model fits the data on age hardening of a solution treated, stretched and subsequently aged $\mathrm{Al}-\mathrm{Cu}-\mathrm{Mg}$ alloy well, which support the proposed strengthening mechanisms.

\section{References}

[1] J.T. Vietz and I.J. Polmear: J. Inst. Met. Vol. 94 (1966), p. 410.

[2] M.J. Starink, N. Gao, L. Davin, J. Yan and A. Cerezo: Phil. Mag. Vol. 85 (2005), p. 1395. 
[3] H Shih, N. Ho and J.C. Huang: Met. Mat. Trans. A Vol. 27A (1996), p. 2479.

[4] S.P. Ringer, T. Sakurai and I.J. Polmear: Acta Mater. Vol. 45 (1997), p. 3731.

[5] L. Reich, S.P. Ringer and K. Hono: Phil. Mag. Lett. Vol. 79 (1999), p. 639.

[6] P. Ratchev, B. Verlinden, P. De Smet and P. Van Houtte: Acta Mater. Vol. 46 (1998), p. 3523.

[7] J.M. Silcock: Journal of the Institute of Metals Vol. 89 (1960-61), p. 203.

[8] A.M. Zahra, C. Y. Zahra, C. Alfonso and A. Charai: Scripta Mater. Vol. 39 (1998), p. 1553.

[9] A. Charai, T. Walther, C. Alfonso, A. M. Zahra, C. Y. Zahra: Acta Mater. Vol. 48 (2000), p.2751.

[10] F. Cuisiat, P. Duval and R. Graf: Scripta Met. Vol. 18 (1984), p.1051.

[11] S.P. Ringer and K.Hono: Mater. Character. Vol. 44 (2000), p. 101.

[12] K. Raviprasad, C. R. Hutchinson, et al.: Acta Mater. Vol. 51 (2003), p. 5037.

[13] L. Davin, PhD thesis, The University of Oxford, 2005.

[14] M.J. Starink, N. Gao and J.L. Yan: Mater Sci Eng. Vol. A387-389 (2004), p. 222.

[15] M.J. Starink, A. Cerezo, J.L. Yan, N. Gao, Phil. Mag Lett, 2006 (in press).

[16] N. Gao, L. Davin, S. Wang, A. Cerezo et al.: Mater. Sci. Forum Vol. 396-402 (2002), p. 923.

[17] M.J. Starink, I. Sinclair, N. Gao, et al.: Mater. Sci. Forum Vol. 396-402 (2002), p. 601.

[18] S.C. Wang, M.J. Starink and N. Gao: Scripta Mater. Vol. 54 (2006), p. 287.

[19] H. Perlitz and A. Westgren: Arkiv. Kemi. Mineral. Geol. 16B (1943), No13

[20] S.C. Wang and M.J. Starink: Int. Mater. Rev Vol. 50 (2005), p. 193.

[21] S.C. Wang and M.J. Starink: Mater Sci. Eng. A Vol. 386 (2004), p. 156.

[22] S.P. Ringer, T. Sakurai and I. J. Polmear: Acta Mater. Vol. 45 (1997), p. 3731.

[23] L. Kovarik, M.K. Miller, S.A. Court, M.J. Mills: Acta Mater. Vol. 54 (2006), p. 1731.

[24] M.J. Starink and J. Yan, Proc. 1st Int. Symp. Metall. Modeling for Al Alloys, Pittsburgh, USA, Sept. 15-17, 2003, p. 119

[25] M.J. Starink and S.C. Wang: Acta Mater. Vol. 51 (2003), p. 5131.

[26] M.J. Starink and A. M. Zahra: Thermochim. Acta Vol. 292 (1997), p. 159.

[27] M.J. Starink and A. M. Zahra: Acta Mater. Vol. 46 (1998), p. 3381.

[28]S.P. Marsh and M.E. Glicksman: Acta Mater., Vol. 44 (1996), p. 3761.

[29] W. Voorhees and M.E. Glicksman: Acta Metall., Vol. 32 (1984), p. 2013.

[30] E. Hornbogen and E.A. Starke: Acta Metal. Mater. Vol. 41 (1993), p. 1.

[31] L. Cartaud, J. Guillot and J. Grilhe: 1976, Proceedings of 4th International Conference on the Strength of Metals and Alloys, Vol. 1 (Nancy, France) pp. 214-218.

[32] M. J. Starink, P. Wang, I. Sinclair and P. J. Gregson: Acta Mater., Vol. 47 (1999), p. 3855.

[33] M.J. Starink and J.L. Yan: Proc. of ICAA10, Vancouver, Canada, 2006, to be published. 